with ascertained relative intensities. This specification was at first no more than an identity 'tag'. When the absolute intensities of absorption could no longer bo changed by repeated recrystallization the substance was deemed to be pure. Various derivatives were prepared and it was eventually shown that $S C$ was isomeric with ubiquinone 50 and was actually a chromene, so that the name ubichromenol became appropriate. Since then an isoprenologue related to ubiquinone (30) has been isolated from Torula yeast. The preparation showed a good optical rotatory dispersion curve and on this basis the ubichromenol could not be an artefact of isolation.

Ubichromenol was originally detected in the livers of vitamin A-deficient rats and was probably derived biologically from ubiquinone 45 , which had a solanesyl side-chain. Ubichromenol was later obtained from human kidney and was related to ubiquinone 50 . It has recently been shown that DL-ubichromenol made in the laboratory from ubiquinone, fully replaces $\alpha$-tocopherol in the gestation-resorption test on rats.

\section{Electron Transport ; Mitochondria}

The sequence of processes which begins with succinate or reduced diphosphopyridine nucleotide and ends with the formation of water at the cytochrome oxidase 'terminus', requires the presence of flavin adenine dinucleotides (FAD), the cytochromes, and other co-factors. Spoctroscopic methods of assay applied to mitochondrial and other preparations allow very satisfactory comparisons to be made of the amount of those catalysts present. Britton Chance, and others, have used ingenious and complicated methods for following rapid processes, but these cannot bo describod here. There is here, however, a fine extension of spectroscopic techniquo.

Biochemists are familiar with the fact that the oxidation-reduction processes which occur with phosphophyridine nucleotides can be followed by changes in absorption at $340 \mathrm{~m} \mu$. A great many enzymatic sequences can be ingeniously brought to a conclusion at this point and some of the most sonsitive micro-analytical processes used by Lowry, and others, make use of the change.

Infra-red absorption spectroscopy has also in recent years witnessed enormous strides in instrumentation, interpretation of data and documentation. The student of natural products can to-day switch from ultra-violet to infra-red absorption as the noed arises, and his efforts can be supported by the growing availability and utility of nuclear magnetic resonance spectra and mass spectra.

- (a) Hershenon, H. M., Vllraviolet and Visible Absorption Spectra Index for 1930-54, 202 (Acad. Press, New York, 1958); (b) Friedel, R. A., and Orchin, M., Ultra-violet Spectra of Aromatic Compounds (Wiley, New York, 1951); (c) Organic Eleetronic Spectral Data $1960,1,1208$ (1946-52); 2, 919 (1953-55) (Interscience, N
York), (d) Mason, S. F., Quart, Rev. 15, 287 (1961).

Isler, O., and Wiss, O., Vitamins and Hormones, 17, 53 (1959). ${ }^{3}$ Francis, J., Madinaveitia, J., MacTure, H. M., and Snow, G. A.,
Nature, I63, 305 (1949).

- Noll, H., J. Biol. Chem., 232, 919 (1958).

'Noll, H., Ruegg, R., Gloor, U., Ryser, R., and Isler, O., Helv. Chim. Acta, 43, 432 (1960).

- Rowland, R. L., Latimer, P. II., and Giles, J. A., J. Amer. Chem. Soc., 78,4680 (1056).

'Erickson, R. K., Shunk, C. H., Trenner, N. R., Anson, B. H., and Folkers, K., J. Amer. Chem. Soc., 81, 4999 (1959).

s Kofler, M., Langemann, A., Rilegg, R., Gloor, U., Schwieter, U., Wursch, J., Wiss, O., and Isler, O., Helv. Chim. Acta, 42, 2252 (1959).

- Pennock, J. F., Hemming, F. W., and Morton, R. A., Nature, 186, 554 (1960).

${ }^{10}$ Täufel, K., and Zimmermann, R., Naturwiss., 47, 133 (1960).

${ }^{1}$ Shugar, D., Biochem. J., 52, 142 (1952).

${ }_{12}$ Ifearn, J. M., Morton, R. A., and Simpson, J. C. E., J. Chem. Soc., 3318 (195i).

${ }^{13}$ Lunn, A. K., and Morton, R. A., Analyst, 71, 845 (1952)

14 Salhanich, H. A., and Berliner, D. L., J. Biol. Chem., 227, 583 (1957).

${ }^{15}$ Morton, R. A., Symposium on Microchemistry, 355 (Pergamon Press, 1959).

${ }^{16}$ Iaidman, D. L., Morton, R. A., Paterson, J. Y. F., and Pennock, J. F., Biochem. J., '74, 541 (1960).

\title{
PARASITES OF WORLD IMPORTANCE
}

$\mathrm{T}$

HE Parasitology Group of the Institute of Biology has adopted the practice of devoting its autumn moeting to a general topic and inviting speakers to discuss various aspects of it. At its meeting held on November 10 at the National Instituto for Medical Resoarch, Mill Hill, tho subjoct chosen was "Parasites of World Importance" and the speakers were invited to discuss problems of distribution ocology and control in relation to a given group of parasites. None of the speakers had any difficulty in demonstrating the world-wide importance of his particular group of parasites, but the way in which oach picked out tho varions aspects of ecology and control proved to bo particularly interesting.

Prof. P. C. C. Garmham (London School of Hygieno and Tropical Medicino), in his discussion of loishmaniasis and Chargas's disease, limited himself to the New World, where they occur together, although leishmaniasis in various forms is also of considerable importanco in the Old World. Trypanosoma cruzi, the cause of Chagas's disease, occurs from Maryland in the United States to Argentina. Its synocology is quito charactoristic and contains an important animal reservoir element which differs from place to place. The incidence of the infection in humans also varies; in some regions of Brazil as many as 60 por cent of the human population may bo infected. Whoro the disease becomes established in man, the importance of wild animals as a reservoir diminishes and domestic animals become important. Transmission is normally by Reduviidae, but in man it may occur via the milk or congenitally. Tho pathogenicity of $T$. cruzi is not understood. In particular, its role in the ætiology of organomogaly is of particular interest.

Leiohmaniasis occurs in two forms, visceral and cutaneous; the former, known as kala-azar, has boen found only relatively recently in South America, where it was first diseovered during the viscerotomy surveys of the Yollow Fovor Sorvice. Now more cases are being disclosed every year, particularly in Brazil and Colombia. Cutaneous leishmaniasis, on the other hand, has been woll recognized perhaps from the preConquest era. It is, however, not ono ontity but many, each with a different æetiology and epidemiology. At least four forms exist, but there are many unsolved problems of differontiation, animal reservoirs and voctors.

Dr. O. D. Standen (Wollcome Laboratories of Tropical Medicine) discussed the species of Schistosoma which infect man, causing disease which has been endemic for thousends of years. Generations of agricultural development with its inevitable organiza- 
tion of water supplies has provided increased opportunities for transmission. It has been estimated that at the present time between one and two hundred millions of the world population are infected; an incidence which is believed to be increasing. The distribution of the three species which infect man $(S$. haematobium found mainly in Africa and more recently in India; S. mansoni in Africa, South America and West Indies; and S. japonicum found in Japan and the Far East) is probably limited by the distribution of the snail vectors. The picture is confused, howevor, by the existence of localized mutually adapted strains of snails and helminths.

With Toxoplasma gondii, Dr. J. K. A. Beverley (University of Sheffield) pointed out that so many species of birds and mammals have been found to be hosts that it is not difficult to believe that any warm. blooded animal may become infected. The infection usually causes little harm, but illnesses, including fatal ones, have been recorded-some epizootics, some local outbreaks and some isolated cases. Infection may be acquired during post-natal life, but congenital infections cause the most damage in both animals and man.

Two particular examples of diseases of worldwide importance caused by Toxoplasma were discussed. Toxoplasmic choroido-retinitis may cause defective vision, hæmorrhage, iridocyclitis, glaucoma or blindness. Diagnosis depends on the situation and the activity of the lesions, but the condition has been found in every country where a proper search has been made. It has been estimated that toxoplasmosis causes 5 per cent of blindness in children in the southeastern States of the United States and that 1.5 per cent of the adult population have scars in the periphery of the fundus. The frequency of lesions causing ocular symptoms in Britain may be more than 1 in 8,000 persons. Ovine abortion due to Toxoplasma is known to occur in New Zealand, Britain and Canada. It is suspected in Australia and India. It has been estimated that in Britain losses may amount to the lambs from 80,000 owes each year.

Plant nematodes were discussed by Mr. F. G. W. Jones (Rothamsted Exporimental Station). Here the problem was to limit the discussion, because examples of nematodes causing great economic loss can be drawn from all over the world. The parasites occur in coconut in the Caribbean, pepper in the East Indies, banana in the Caribbean, Australia and Israel, citrus in Florida, rice in Japan, the Philippines and India, tobacco and cotton in Africa, peaches in Canada, vines in California and Portugal, sugar beet in Europe and the United States, cereals, potatoes, flower bulbs, lucerne and elover in Europe. In fact, all countries and all crops probably have their eelworm problems, and there is great need, especially in the less developed countries, for surveys to determine what nematode problems exist and to assess their degree of importance.

Dr. E. L. Taylor (Central Veterinary Laboratory, Weybridge) was faced with a similar problem in discussing "Veterinary Helminths". Some 10,000 species of worms have a parasitic mode of life and of these species about 800 occur in domestic and furbearing animals. The increased concentration of grazing animals made possible by improved pasture management adds greatly to the risks of over-infestation with strongyloid worms. The most serious economic effect undoubtedly comes through the depression of the growth-rate in young animals, its insidious nature adding to the difficulty of arriving at an accurate picture. Many of the harmful helminths are of world-wide distribution, and it is only a proportion that are restricted by climate or intermediate-host requirement to certain regions. In some ways it is the most developed countries that suffer the most loss, because of the greater concentration of stock.

Another serious parasitological problem is human onchocerciasis. This was discussed by Dr. D. J. Lewis (Medical Research Council, British Museum-Natural History) against the background of the ecology of the insect vectors, the Simuliidae. Onchocerca volvulus is a filarial nematode and is known in tropical Africa, Guatemala, Mexico and Venezuela. It probably reached America with the slave trade, where it found suitable vectors in $S$. ochraceum and $S$. metallicum. Although the important vectors are few, the ecological factors which control its distribution are complex.

For the control of these parasites a detailed understanding of their biology is essential and much remains to be learned. Ignorance of the mode of transmission of toxoplasmosis, for example, is limiting progress, and further research is needed on the possibility of onchocerciasis control by partial control of Simulium. Plant nematodes may sometimes be controlled by crop rotation and on advice based on soil sampling and a knowledge of host-ranges and population changes with cropping. Much remains to be learned, but work on soil structure, moisture and aeration is yielding useful information on the soil phase in plant nematode life-cycles.

The immunity of the host represents an important factor in the environment of the animal parasite as well as offering a basis for diagnostic methods. In this field also important problems are outstanding, particularly in leishmaniasis and schistosomiasis.

Chemotherapy offers hope of some success in controlling the parasites, but many problems remain. In the case of Chagas's disease, no curative drug has yet been found. Similarly, with schistosomiasis, no material advance has been made since the introduction of tartar emetic in 1918. During the post-war years a wide search for new drugs has failed to produce any progress towards the ultimate goal of simple treatment with a highly effective drug. Much research has also been directed towards the treatment and prevention of toxoplasmosis. Here the use of nonspecific antiphlogistic cortico-steroids is a valuable adjunct to specific therspy, mainly with potentiated sulphonamides. In the field of veterinary anthelminthics steady progress has been made, so that in recent years a series of compounds has become available with increasing efficacy. Dr. Taylor, however, made the point that under the conditions of modern intensive husbandry, it is important to maintain a level of resistance in the host animals. Where this is dependent on the presence of a low level of infection, highly effective drugs would need to be used with care.

The application of chemical substances to plant nematodes poses considerable problems. Many toxic substances are immobilized, detoxicated or destroyed when applied to soil. However, some plants, such as Tagetes and Asparagus, contain principles in their roots which are highly toxic to nematodes, and other plant nematicides may be found. A nematicidal dip or other treatment that would disinfest transplants or nursery stock would solve many problemsespecially quarantine problems, for many potentially harmful nematodes are spread when their hosts are moved from place to place. 
Control of the vectors with residual insecticides offers a means of controlling Chagas's disease, but for onchocerciasis in particular it is necessary to find insecticides which will not harm predators or fish required for human food.

Even where work on the biology of the parasites has suggested possible methods of control, their implementation sometimes poses great social or economic problems. Control of Chagas's disease is ultimately a question of good housing, which is controlled by economic factors. Public health measures in hygiene and sanitation could, in theory, eliminate schistosomiasis by prevention of contact between fresh human excreta and water, but adequate education and the supervision necessary have yet to be achieved.

The proceedings of this meeting will not be published in detail.
L. P. JOYNER

\title{
EFFECT OF LYSERGIC ACID DIETHYLAMIDE ON THE SURFACING BEHAVIOUR OF LARGE CARP
}

\author{
By Dr. H. A. ABRAMSON, H. H. GETTNER, M. P. HEWITT and G. DEAN \\ The Biological Laboratory, Cold Spring Harbor, Longllsland, New York
}

L

OEB has stated" that "None of 1,800 assorted compounds force-fed to carp has produced more than random surfacing or any directed movements of the fish". Any class of compounds which produces surfacing and directed movements of carp, therefore, can be of importance in the control of fish populations, as well as in the study of the physiology of the fish themselves ${ }^{2}$. It is the purpose of this article to show that a group of compounds related to lysorgic acid diethylamide (LSD-25) produces surfacing behaviour of carp with the movement directed toward the surface, thus providing the pharmacological effect that has been sought through forced feeding. Our experiments have not, as yet, included feeding these drugs to fish, although extensive work on man would indicate that the material is absorbed from the intestinal tract. The drugs are active when given intraperitoneally to Siamese fighting fish ${ }^{3}$.

It has been shown previously from work in this laboratory that very small quantities of derivatives of lysergic acid, like lysergic acid diethylamide (LSD-25) and lysergic acid ethylamide (LAE-32), have a surfacing effect on small Siamese fighting fish $(0.3-5.0 \mathrm{gm}$.). Less than $0.5 \mu \mathrm{gm}$. per ml. of LSD-25 in the outside liquid causes most of the fish to go to the surface of the liquid and remain relatively immobile. $1 \mu \mathrm{gm}$. per ml. results in almost 100 per cent surfacing ${ }^{3-5}$.

Preliminary experiments have shown that both LSD-25 and LAE-32 affect small goldfish and Siamese fighting fish in a somewhat similar manner. However, it was found that larger tanks were needed to make quantitative observations. Our work with goldfish confirmed what had been known at this laboratory for many years, since the goldfish was one of the first type of fish investigated after our observations had been made on Siamese fighting fish. This article deals primarily with the effect of small concentrations of psychotomimetic amines on large carp.

Through the kindness of Mr. Howard A. Loeb of the New York State Conservation Department, carp at least $2 \mathrm{lb}$. in weight were sent to this laboratory for study. The fish, all more than 12 in. in length, were kept in a running spring close to the laboratory. During the course of the experiments air was bubbled through the tanks containing the control and experimental carp. Both the control and experimental tanks (capacity 44 litres) contained three carp weigh- ing approximately $2 \mathrm{lb}$. each. $88 \mathrm{mgm}$. of LSD-25 were dissolved in the water of the experimental tank. After the fish had been exposed to LSD-25 for $10 \mathrm{~min}$. they showed signs of LSD-25 activity. After $30 \mathrm{~min}$. all three fish in the tank containing LSD-25 were at the surface of the liquid in a nose up-tail down position, with the control fish showing some restlessness but remaining at the bottom of their tank (Fig. 1). For the next hour the fish in the tank containing LSD-25 remained at the surface, from time to time moving and even swimming backwards. Of course, they were somewhat cramped in the small tanks and their movements were governed, perhaps

Tank 1

$2 \mathrm{mcgm} . / \mathrm{ml}$. LSD-25

Tank 2

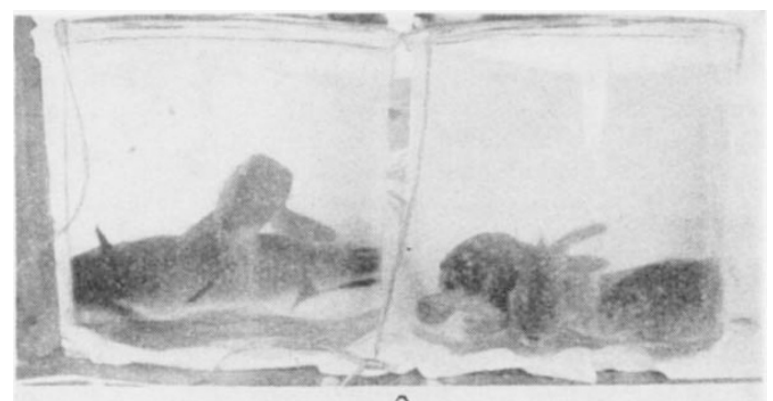

0

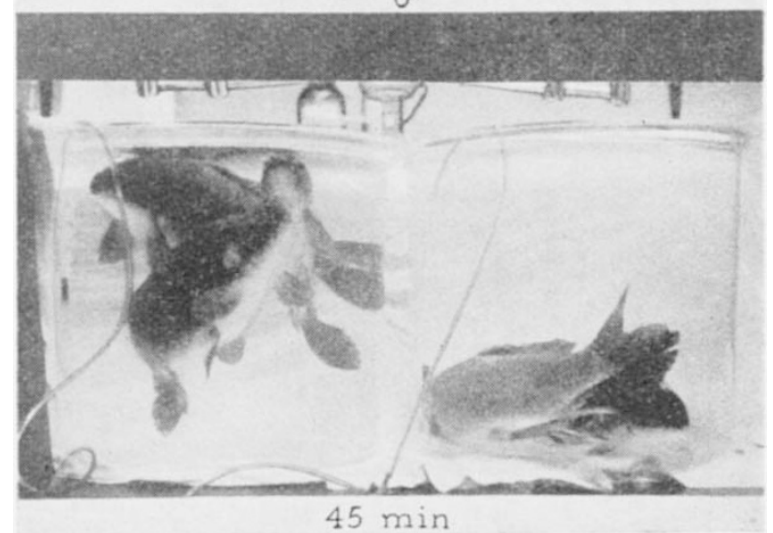

Fig. 1. The effect of LSD-25 on large carp. Tank 2 is the control. Typical surfacing behaviour due to LSD-25 is shown by the fish in Tank 1 which contains $2 \mu \mathrm{gm}$. $/ \mathrm{ml}$. LSD-25. The size of the fish 